\title{
Florida Atlantic University
}

The Florida Atlantic University at Boca Raton is a new institution. Among its several departures is its plan to operate a library which will incorporate the latest technological developments. The next three papers discuss some of the concepts and principles, as well as some of the basic procedures, upon which the FAU library is being organized.

\section{New Libraries on New Campuses}

\section{BY EDWARD HEILIGER}

WITHIN THE PAST FEW YEARS, the author has taken part in the planning of libraries for two new campuses; one for the University of Illinois at Chicago, and one for the Board of Control for Higher Education at Boca Raton, Florida. The latter has been named Florida Atlantic University. There is one important difference between the two. The library at the new campus in Chicago has been developed over a period of sixteen years. The library at Florida Atlantic University has been started this year. The same is true of the faculty for the two institutions, although on the Chicago campus there will be a great expansion of the faculty in the near future.

How does a new library differ from one that has grown over a period of years? First, the library staff differs. Starting with a clean slate, it is possible to set up an adequate salary scale, one which is not tied to an old outlook. Librarians can now command good salaries. In a new situation, it is possible to establish this fact and set up a corresponding salary scale. At Florida Atlantic University, the beginning
Mr. Heiliger is Director of the Library and Information Retrieval Services at Florida Atlantic University, Boca Raton. This paper was presented at the 49th Conference of Eastern College Librarians, November 30, 1963, New York City.

salary for librarians just out of library school is $\$ 7,800$ a year. Faculty status for the professional library staff, which is sometimes difficult to establish in an old situation, is relatively easy to arrange on a new campus. There are those who argue against faculty status for library staff. At Florida Atlantic University, where the library staff is expected to become much more involved in the teaching program, it is essential. The library staff at the University of Illinois in Chicago has always had faculty status, and it is expected that this arrangement will continue on the new campus.

At Florida Atlantic University, the director of library and information retrieval services was hired with the stipulation that he would develop a computer-based library system. This called for staffing 
with librarians who were sympathetic to this idea and were somewhat knowledgeable in the field of data processing. It also called for a staff that could approach the development of this system with an open mind and a willingness to adjust to it. This is a creative situation for a library staff and a challenge on which to bring to bear the result of its previous professional experiences.

The new university develops its own philosophy within which the library on a new campus must function. In Chicago, building and curriculum planning for the new campus was done by the faculty, including the library staff, over a period of several years. This was done by a faculty of approximately three hundred and fifty people that expected to work on the new campus and that took part in the planning of the buildings. In Florida, the work of over-all planning was handed to a commission by the Board of Control for Higher Education of Florida. The planning done by this commission had strong effects on the architectural planning of the first phase of the campus. The faculty that will be teaching on the new campus was not involved in laying down these guidelines, nor in planning the first-phase buildings. For curriculum planning in August and September of 1963 a planning workshop was held for the small group of faculty that had been appointed, and a large number of outstanding consultants was retained from universities around the country. The library staff was closely involved in planning the library building during a three-year period at Chicago. In Florida, the library staff had nothing to do with planning the library building itself, but it is involved in the equipping and arranging of facilities within the building. The library staff took part in the planning workshop in Florida.

The library on the established campus usually has the assistance of a faculty library committee. On a new campus, the library often does not have this support until the faculty organization is complete. Some way must be developed to get faculty support for library needs, inasmuch as faculty needs are vital to the library's work. A new campus situation offers the library staff an opportunity to make another attempt to integrate the library more closely with the teaching program. At Florida Atlantic University, a high level position is being established on the library staff called Director of Liaison Services. It will be this person's business to keep track of what each professor is doing in each course and in his research work. He will make suggestions to the individual professors about ways in which the library can help him. He will then report to different members of the library staff about his findings, obtain further ideas, and relay them to the professor.

The structure of the new university calls for certain library orientation. Early in the planning of Florida Atlantic University, it was decided to have the library as one part of a large Learning Resources Area which would include five divisions. The other divisions are television and radio, learning laboratories, graphics, and learning resources facilities. The library catalog will be a catalog of not only the library materials but also other materials that will be available through the Learning Resources Area. These include: slides, films, film strips, and other visual and audio materials. The director of learning resources is responsible to the president. Another unusual facet of the relation of the library to the rest of the university is the problem of fitting the computer system developed in the library into the computer system being planned for the registrar, the business office, and the research areas in the university.

The faculty coming to a new university brings with it orientation to differing library situations. Although faculty members are alerted to the fact that they will find a different library situation, they still tend to assume that the library in the new 
situation will be very similar to the library to which they are accustomed. They also frequently bring ideas about how the library on the new campus should not perpetuate some of the evils (as they see them) of the library in the institution from which they have come.

The selection of the book collection of a new library is a serious problem. The University of California, for its three new campuses, in La Jolla, Orange County, and Santa Cruz, hired a book selection team to develop a basic collection for the three campuses. The work of selection and of ordering was under the supervision of Joe Treyz. Most of the books were ordered through Bro-Dart Books and came supplied with Library of Congress cards. At Florida Atlantic University it was decided to order the same titles as have been ordered for the California campuses. Ordering was also done through Bro-Dart Industries and their processing service was also purchased. The books will be delivered with IBM book cards, with the LC classification number punched in; with book pockets; plastic book jackets; and the call number on the spine of the book. Bro-Dart may also supply Library of Congress cataloging punched into IBM cards. At present, a set of LC cards is being delivered with each book, and it is planned that one card will be used for a card shelflist and some of the other cards for experimenting with coding of cataloging for computer input. This service from Bro-Dart costs $\$ 1.60$ per volume. The average discount from them comes to about $\$ 1.50$ per volume so that the total cost is about $10 \mathrm{c}$ per volume over the list price of the book. The twenty-five thousand volumes which are being got from Bro-Dart on this California plan represent about one-third of the collection which is anticipated will be on hand when the library opens on September 1, and do not include out of print or foreign language material, or much of the science selection. The time element in building a collection for a new university library differs greatly from building such a collection over a long period of years. Building a good collection should take a long time, but seldom does a library in a new situation have that kind of time. Taking advantage of this time effort by the University of California is saving FAU a great deal of time and effort. Progress is now being made on cost studies to determine the average cost of coding cataloging copy for computer input.

Older libraries often lament the amount of "dead wood" which they have. Anyone facing a new library situation soon develops an envy for older institutions just because of their "dead wood." Florida Atlantic has taken steps to acquire some of the older titles by purchasing Burt Franklin's collection. This antiquarian collection numbered about forty thousand volumes. There was an immediate need for listing these. Clerks, under the supervision of a cataloger, were set to coding for IBM listing. Each clerk, working directly from books, was able to code about thirty books an hour. The key punch operator could do each thirty in about ten minutes. The printout is by author, but it can also be by short-title or by fixed classification number. This, it is felt, is an excellent technique for listing bloc purchases.

A library in a new university has a chance to tackle anew the problem of centralization of library facilities. In Chicago, establishing a policy of centralization in library facilities was much more difficult because the faculty was on hand to express an opinion. The matter was discussed pro and con and finally went to the president for a decision. Urbana campus experience with the library system, which included thirty-five special libraries, with its duplication of books, journals, and staff, plus the inefficiencies evident in a situation where the special libraries could not be kept open many hours, probably influenced the decision. In both Chi- 
cago and Boca Raton the buildings have been grouped closely together and are joined by covered walkways. This makes the campus seem to be in one very large building. Therefore it is easier to persuade the faculty to go to the central library. In Chicago, in the architectural planning for the new campus, it was specified that no more than one wall of any one room in any department could have book shelves. Both in Chicago and in Florida, planning included multiple copies of a printed catalog, with a copy in each faculty department, as well as in different places in the central library. This, plus a promise of frequent delivery service in response to telephone requests, has mollified the faculty.

As both campuses are planning computer-based library systems, something should be said about this. The system was researched on the Chicago campus and is being implemented on the Florida campus. It has been described in book form. ${ }^{1}$ In brief, the system calls for:

1. Use of an IBM 1401 type of computer.

2. A computer-produced catalog.

3. Computer printout of book orders, overdue notices and lists, claims notices, budget information, binding lists, bibliographies, and dissemination notices.

4. A dissemination program similar to the one being used internally by IBM today. Faculty reading interest will be put on a tape that will be matched with the tape of incoming materials to produce notices addressed to individual faculty members telling them that a particular book has arrived that may be of interest to them.

5. Printout of the following control documents:

A. A processing information list, a frequently updated list showing the

${ }^{1}$ Louis A. Sehultheiss, Don S. Culbertson and Edward M. Heiliger. Advanced Data Processing in the University Library (New York: Scarecrow Press, 1962), 388p. whereabouts of items being processed by the library.

B. A daily circulation list, posted at different places in the stacks, which will tell readers which items are in circulation (or other special locations), and when they are due back.

C. A current serials list (three times a week) showing arrivals of current journals, expected arrival dates.

D. A serials holdings list, annual, showing the complete holdings of journals.

Although at Florida Atlantic University, the system is to become operative on September 1, in Chicago, where campus building matures somewhat later, the date will probably be a year later. In both cases, it will be much longer before the system will be functioning perfectly. At FAU, a coding system for putting cataloging copy onto computer tape in such a way that a satisfactory printed catalog will result has been achieved. The entire library staff is practicing the new technique. The coding system for serials is being tested on both campuses. At Florida Atlantic, the computer program for output of the serials check-in cards has been written and carefully checked.

Finally, equipment budgets never seem adequate. In planning a new library on a new campus, there is an opportunity to equip the library completely with the latest and best equipment. In both Chicago and Florida, the data processing approach requires considerable equipment, and particular attention must be paid to the computer center and its equipment. At the present time Florida Atlantic University is having long discussions on the number of characters which will be needed on a computer chain that will have to be bought just because of library needs. The registrar and the business office are not interested in a sophisticated printout, but some of the research people in physics and chemistry realize the need for an ade- 
quate printout, and there is support from them.

Finally, it should be observed that a new library finds itself setting policy on different matters almost every day. This calls for a careful examination of the old way of doing things and consideration of the newest way.

\section{The Computerized Book Catalog At Florida Atlantic University}

\section{By JEAN M. PERREAULT}

IN THE AUTOMATION of library work (or, if you will, its computerization) the catalog must be considered one of the primary targets. One of the principal concerns of the extensive research at the Chicago campus library of the University of Illinois, resulting in the treatise Advanced Data Processing in the University $\mathrm{Li}$ brary, ${ }^{1}$ was the preparation of an outline of what could be done to bring the catalog into the frame of reference of the computer. The research of the University of Illinois, Chicago staff and their General Electric consultants was primarily theoretical. The research was essential but it by no means automatically brought about the solution of the problem. This solution is not directed primarily toward any new problems; it is and must be a solution for the same problems that always have been with every cataloger. But often the presence of these problems has been almost ignored because of an accumulation of too-easy, halfway solutions to dimly seen problems. Automation has the inestimable advantage over any conventional cataloging system. It cannot allow solutions which do not solve because they do not need to-their users will keep them from succumbing to their own unexamined flaws. Automation cannot allow any such "system-flaws," because when such a system is turned over to a computer for manipulation, it will give results which re-

1 (New York : Searecrow Press, 1962.)
Mr. Perreault is Chief of Cataloging in Florida Atlantic University in Boca Raton.

flect precisely the degree of intensity given to the solution of problems before they arise. Systems-design is an activity worth all the time any cataloger can give to it, even those who have no intention of investing in computer hardware.

The configuration of the input document as designed by the staff of the University of Illinois, Chicago library can be described as a "bibliographic string" modeled on the tradition of cataloging at present embodied in ALA and LC cataloging rules, but with the addition to this string of "knots" occurring wherever a new element begins. These knots are symbolized on the input document in a series of numbers representing to the computer the function of the element of the catalogtext that is associated with it.

In the course of a great many conferences, notably with Louis Schultheiss of the University of Illinois, Chicago library staff and with Frederick Kilgour of the Yale medical library, several important modifications were developed in the Florida Atlantic University form of cataloging for computer manipulation. Each area of the input document was reduced to the crucial length below which reductions would begin to affect a considerable number of entries in such a way as to reduce their fullest usefulness. Flexibility was a 